\title{
Nicotine patches in pregnant smokers: randomised, placebo controlled, multicentre trial of efficacy
}

\author{
(c) $(1)(8)$ OPEN ACCESS
}

\author{
Ivan Berlin senior lecturer, hospital practitioner ${ }^{1}$, Gilles Grangé hospital practitioner ${ }^{2}$, Nelly Jacob \\ hospital practitioner ${ }^{3}$, Marie-Laure Tanguy statistician ${ }^{4}$
}

'Département de Pharmacologie, Hôpital Pitié-Salpêtrière, Assistance Publique-Hôpitaux de Paris, Université Pierre et Marie Curie-Faculté de Médecine, INSERM Unité 669, Paris, France; ${ }^{2}$ Maternité Port-Royal, Assistance Publique-Hôpitaux de Paris, Paris, France; ${ }^{3}$ Département de Pharmacologie, Hôpital Pitié-Salpêtrière, Assistance Publique-Hôpitaux de Paris, France; ${ }^{4}$ Unité de recherche clinique, Hôpital Pitié-Salpêtrière, Assistance Publique-Hôpitaux de Paris, Paris, France

\begin{abstract}
Objective To determine the efficacy of 16 hour nicotine patches among pregnant smokers, with the dose individually adjusted according to saliva cotinine levels (potential range 10-30 mg/day).

Design Randomised, double blind, placebo controlled, parallel group, multicentre trial (Study of Nicotine Patch in Pregnancy, SNIPP) between October 2007 and January 2013.

Setting 23 maternity wards in France.

Participants 476 pregnant smokers aged more than 18 years and between 12 and 20 weeks' gestation, who smoked at least five cigarettes a day. After exclusions, 402 women were randomised: 203 to nicotine patches and 199 to placebo patches. Data were available on 192 live births in each group.

Interventions Nicotine and identical placebo patches were administered from quit day up to the time of delivery. Doses were adjusted to saliva cotinine levels when smoking to yield a substitution rate of $100 \%$. Participants were assessed monthly and received behavioural smoking cessation support.

Main outcome measures The primary outcomes were complete abstinence (self report confirmed by carbon monoxide level in expired air $\leq 8 \mathrm{ppm}$ ) from quit date to delivery, and birth weight. The secondary outcomes were point prevalence of abstinence, time to lapse (a few puffs) or relapse, and delivery and birth characteristics. All data were analysed on an intention to treat basis.
\end{abstract}

Results Complete abstinence was achieved by $5.5 \%(n=11)$ of women in the nicotine patch group and $5.1 \%(n=10)$ in the placebo patch group (odds ratio $1.08,95 \%$ confidence interval 0.45 to 2.60 ). The median time to the first cigarette smoked after target quit day was 15 days in both groups (interquartile range 13-18 in the nicotine patch group, 13-20 in the placebo patch group). The point prevalence abstinence ranged from $8 \%$ to $12.5 \%$ in the nicotine patch group and $8 \%$ to $9.5 \%$ in the placebo patch group without statistically significant differences. The nicotine substitution rate did not differ from $100 \%$, and the self reported median compliance rate was $85 \%$ (interquartile range $56-99 \%$ ) in the nicotine patch group and $83 \%(56-95 \%)$ in the placebo patch group, assessed at 1016 visits. The mean birth weight was $3065 \mathrm{~g}$ (SE $44 \mathrm{~g}$ ) in the nicotine patch group and $3015 \mathrm{~g}$ (SE $44 \mathrm{~g})$ in the placebo patch group $(\mathrm{P}=0.41)$. Diastolic blood pressure was significantly higher in the nicotine patch group than in the placebo patch group. The frequency of serious adverse events was similar between the groups, although more non-serious adverse reactions, mainly of skin, occurred in the nicotine patch group.

Conclusion The nicotine patch did not increase either smoking cessation rates or birth weights despite adjustment of nicotine dose to match levels attained when smoking, and higher than usual doses.

Trial registration ClinicalTrials.gov NCT00507975.

\section{Introduction}

Smoking during pregnancy increases the risk of adverse pregnancy and birth outcomes ${ }^{1}$ and may have long lasting effects in offspring. ${ }^{2-4}$ Despite relatively high spontaneous smoking cessation rates among pregnant smokers, smoking during pregnancy remains a major public health issue. A meta-analysis of interventions to help pregnant smokers quit has shown a modest overall efficacy on abstinence (risk ratio $0.94,95 \%$ confidence interval 0.93 to 0.96$).{ }^{5}$ The addition of nicotine replacement therapies (NRT) to behavioural smoking cessation interventions in pregnant smokers is based on their excellent safety profile and proved efficacy in other populations of smokers. Several statements have called for the immediate implementation of well conducted clinical trials. ${ }^{1-8}$

Despite a lack of conclusive evidence on the use of NRT for smoking cessation in pregnant women, such treatment is recommended by French and UK health authorities, ${ }^{9}{ }^{10}$ but not by US guidelines. ${ }^{11}$ Previous trials had insufficient power to draw conclusions about the efficacy and safety of NRT in pregnancy. ${ }^{12-16}$ Two recent meta-analyse ${ }^{17}{ }^{18}$ and one sufficiently powered recent study ${ }^{19}$ concluded that NRT are not effective in 
helping pregnant women to stop smoking. However, previous studies only assessed doses of up to $15 \mathrm{mg}$ of nicotine a day, ${ }^{12} 19$ had a duration of exposure of not more than eight weeks, reported low compliance rates, and did not adjust the daily nicotine dose on an individual basis. Adjustment of the daily dose is important because the metabolism of nicotine is accelerated during pregnancy, ${ }^{20-22}$ and standard doses can result in under-dosing and consequently less efficacy. Individual dose adjustment could allow a close to $100 \%$ substitution rate and also avoid overdosing, which may potentially lead to an increased risk of adverse events.

To tackle the lack of information on the safety and efficacy of NRT in pregnant smokers, the French Ministry of Health initiated a public grant application in 2005. In response to this initiative we performed a multicentre, double blind, randomised, placebo controlled, parallel group, nationwide study to assess the efficacy of 16 hour nicotine patches, with doses individually adjusted and potentially ranging from $10-30 \mathrm{mg} /$ day.

\section{Methods}

\section{Recruitment}

We recruited pregnant smokers through advertisements in pharmacies, maternity wards, primary care doctors' offices, and a website dedicated to the study (www.snipp.fr). Moreover, in two waves the National Institute for Prevention and Health Education (Institut national de prévention et d'éducation pour la santé, INPES) sent out 20000 letters to general practitioners, obstetricians, and pharmacists. This mailing contained the study's flyer on aims, study design and interventions, and main inclusion criteria for prescreening of potential participants. It also contained a letter asking for pregnant smokers who were motivated to quit to be referred to the closest study centre.

\section{Inclusion and exclusion criteria}

We included pregnant smokers aged 18 years or more with a gestational age of between nine and 20 weeks of amenorrhea who smoked at least five cigarettes a day and scored at least 5 on a motivational scale of quitting smoking (range 0-10). Participants had to be affiliated with a health insurance system, as required by French law on biomedical research. Exclusion criteria included refusal to use transdermal nicotine patches or placebo patches; use of neuroleptics, antidepressants, or anxiolytics for a chronic psychiatric disorder; a skin disorder contraindicating the use of patches; use of another tobacco product other than cigarettes; current and previous month's use of any NRT; or use of either bupropion or varenicline, as they are contraindicated in pregnancy. Twin pregnancy was not an exclusion criterion.

Participants signed a written informed consent form, and the father of the unborn child also signed a written informed consent form to allow the recording of the newborn's data, as required by French law on biomedical research.

\section{Study design}

The study was conducted in 23 maternity wards throughout France. Participants were assigned to receive either nicotine or placebo patches with an allocation ratio of 1:1. All study staff (investigators, pharmacists, members of the coordination centre and of the drug safety monitoring board, laboratory staff, statistician) were double blinded to treatment allocation.

After a telephone interview, potential participants attended the inclusion visit for detailed information about the study, determination of saliva cotinine levels, counselling for smoking cessation, and data collection. The next randomisation visit was scheduled after a grace period of at least two weeks, thus permitting the participants to quit smoking or reduce the number of cigarettes to fewer than five a day. If participants failed to do either of these, they could be randomised, receive the study drug, and set a quit date. The grace period was necessary because the marketing authorisation for NRT stipulates that it is mandatory to first ask people to stop smoking without NRT; NRT should only be prescribed to pregnant smokers if they are unable to quit. Treatment started on the quit date, in line with marketing authorisation of NRT in France. Study drugs were used from the quit date until delivery. We telephoned participants who missed a visit, and if there was no response we sent a reminder letter. At each visit, participants were reminded about the risk of smoking on pregnancy outcomes, not to smoke, to use patches, and to attend visits even if they experienced a relapse. Co-use of a nicotine patch with cigarettes was a safety concern, but in the absence of evidence based data, pharmacovigilance alert, and lack of disposition for it in the marketing licences for NRT, the women were permitted to stay in the study despite a relapse. Moreover, the adjustment of nicotine dose could potentially lead to reduced nicotine uptake from cigarettes.

The second visit for saliva cotinine levels was two weeks after quit date (visit 2), followed two weeks later by the dose adjustment visit (visit 3 ). A third saliva cotinine sample was taken eight weeks after the quit date (visit 4), and dose adjustment done 12 weeks after the quit date (visit 5); this dose was maintained up to delivery. Altogether, we planned seven visits, with the last occurring about one month before delivery. A follow-up visit was scheduled for two months after delivery. We planned monthly visits because more frequent ones could potentially compromise adherence to the trial protocol and result in a high no-show rate. However, to reach the effective nicotine dose as soon as possible we intercalated a sampling visit at week 2 after quit date because in smoking cessation studies relapse occurs mainly during the first month of treatment. ${ }^{23}$

\section{Interventions}

We used 16 hour delivery nicotine patches (Nicorette; McNeil, Johnson \& Johnson, Helsingborg, Sweden) and identical placebo patches. The placebo patches were specifically manufactured for this study and underwent adequate quality control. We used $10 \mathrm{mg}$ and $15 \mathrm{mg}$ patches, and the daily dose ranged from 10-30 $\mathrm{mg} /$ day. Because marketing authorisation also depends on data about a drug's bioavailability, the use of licensed nicotine patches guaranteed the bioavailability of nicotine. This is particularly important for transdermal delivery systems, which need to be manufactured in a specific way, and lack of data on bioavailability for unlicensed nicotine patches may raise the possibility of low bioavailability and, consequently, can be a source of low or no efficacy.

The first prescription for a patch was based on the saliva cotinine levels at the inclusion visit, when the participants still smoked. To obtain the daily nicotine dose we used a conversion factor of 0.1 of the saliva cotinine concentration. For example, if the concentration was $100 \mu \mathrm{g} / \mathrm{L}$, the investigator received an automatic prescription of one $10 \mathrm{mg}$ patch, signed it, and the study's pharmacist delivered one $10 \mathrm{mg}$ patch. The nicotine to plasma cotinine conversion factor has been estimated to be 0.08 ( $95 \%$ confidence interval 0.05 to 0.10 ) after intravenous nicotine has been administered or a cigarette smoked, ${ }^{24}$ meaning that 1 $\mathrm{mg}$ of nicotine leads to a $12.5 \mu \mathrm{g} / \mathrm{L}$ increase in the plasma cotinine concentration. The systemic nicotine intake for each 
cigarette has been estimated to be $1.17-1.31 \mathrm{mg}^{25}$ and $0.26-1.47$ $\mathrm{mg} .{ }^{26}$ For practical reasons, we considered the nicotine intake from a cigarette to be $1 \mathrm{mg}$. We based the next two dose adjustments on the two previous saliva cotinine results after the quit date - that is, post-randomisation cotinine levels as a percentage of baseline according to the formula: (baseline saliva cotinine concentration-current saliva cotinine concentration)/10(mg of nicotine)+number of cigarettes smoked during past seven days $/ 7 \times 1 \mathrm{mg}$ of nicotine. We defined a prescription dose as the nominative patch dose prescribed for either nicotine or placebo patches.

Saliva samples were kept at $4{ }^{\circ} \mathrm{C}$ in the maternity wards and transported within 48 hours to the central laboratory (Hôpital Pitié-Salpêtrière, Département de Biochimie). The saliva cotinine level was determined as previously described ${ }^{27}$ in less than one week and the results posted on the electronic case report form. This form calculated the patch dose that investigators needed to prescribe. Determinations of saliva cotinine levels were carried out blinded. The investigators were not aware of the results.

Participants received behavioural support at each visit. The strongest such support was provided at the randomisation visit, which lasted one hour. Investigators, who were doctors or midwives, had been specifically trained and received a diploma in smoking cessation. Although the personalised, individual behavioural interventions were not specifically standardised, and the participating maternity wards could use their discretion to apply their own standard methods, these interventions were based on the national consensus document. ${ }^{28}$ All investigators used this document. In the main document on help with quitting smoking, ${ }^{28}$ detailed recommendations are given on how to deal with pregnant smokers (question 3, page 15/37) and there are also specific recommendations about psychological/behavioural interventions (chapter 4.1, page 17/37). Moreover, the study's website (www.snipp.fr) along with flyers in waiting rooms provided information that participants would receive personalised (not within groups) interventions by healthcare professionals specialised in smoking cessation. The investigators had to be committed to deliver at least 10 minutes of counselling at each visit and they were reminded about this during annual investigators' meetings (slide in French available on request).

The core feature of the behavioural interventions included motivational interviewing, arrangement for follow-ups, behavioural counselling, establishment of good doctor-patient and midwife-patient relationships, and a clear definition of treatment aims. We reviewed and discussed the behavioural interventions at each investigators' meeting.

\section{Power calculations}

\section{Main outcome measure: smoking abstinence}

At the time of the power calculations, two previous studies ${ }^{12} 13$ had not shown a difference in abstinence rate. Self initiated smoking cessation with biochemical confirmation in early pregnancy among women not seeking smoking cessation treatment in pregnancy has been reported as high as $65 \%$ to $81 \% .{ }^{29} \mathrm{We}$ conservatively hypothesised a complete abstinence rate from quit date until delivery of $10 \%$ in the placebo patch group and $20 \%$ in the nicotine patch group $(\alpha=0.05,1-\beta=80$, two tailed test) among study participants: women seeking smoking cessation treatment in pregnancy who were unable to reduce their cigarette consumption to fewer than five cigarettes a day. This resulted in the randomisation of 219 pregnant smokers in each group. However, because of time constraints imposed by the funder, we stopped recruitment after 403 participants had been randomised. With 203 participants in the nicotine patch group and 199 in the placebo patch group, the study had a power of $77 \%$ to detect a difference of $10 \%(10 \%$ in the placebo patch group and $20 \%$ in the nicotine patch group) with $\alpha=0.05$, which was close to the planned power of $1-\beta=80$.

\section{Main outcome measure: birth weight}

We calculated $(\alpha=0.05,1-\beta=80$, two tailed test $)$ that with 219 pregnant smokers in each group and with a common standard deviation of $350 \mathrm{~g}$ we could have shown a between group minimal, statistically significant difference of $100 \mathrm{~g}$, which we considered as clinically significant. Power calculations to detect a significant difference at $\mathrm{P} \leq 0.05$ between the nicotine patch and placebo patch for serious adverse events showed that at least 800 pregnant smokers would need to be randomised in each group - that is, the study would have insufficient power to detect a significant difference for serious adverse events. Therefore, we did not carry out statistical comparisons for adverse events.

\section{Randomisation}

A computer generated randomisation list (allocation ratio 1:1) in blocks of four was prepared and kept double blinded. Sixty randomisation numbers were established by centre. In case of more than 60 randomisations by centre, the next randomisation list of 60 was added. The randomisation list by centre was incorporated into the electronic case report form, and the randomisation number was attributed automatically at the completion of the randomisation visit. A statistician at the clinical research centre of the Assistance publique-Hôpitaux de Paris, who was fully independent of the trial, prepared the random, computer generated allocation sequence. The randomisation code was kept in a sealed envelope in a safe. A copy of the randomisation code was kept separately in case of a serious adverse event necessitating exposure of a participant's group assignment. Investigators, members of the coordination centre, hospital pharmacists, and the study statistician were kept blinded until the code was opened before witnesses on 19 February 2013.

\section{Outcome measures}

\section{Main outcome measures}

Because the study involved two participants (mother and child), we used two main outcome measures. The main outcome measure for the mother was complete, continuous abstinence since quit date, which was defined as abstinence at each visit (self report of abstinence during the past seven days and carbon monoxide level in expired air $\leq 8 \mathrm{ppm}$ ). We used this stringent abstinence criterion because during pregnancy only full abstinence could completely eliminate smoking induced complications; the birth weight of infants born to women who quit is higher than for those born to women who cut down on their cigarette consumption, and reduction in smoking has either no or a negligible effect on gestational age at delivery. ${ }^{30} 31$ The main outcome measure for the newborn baby was birth weight.

\section{Secondary outcome measures}

Secondary outcome measures for the mother included point prevalence abstinence defined as self reported smoking abstinence in the past seven days confirmed by carbon monoxide level in expired air and time (days) to first cigarette after quit date (lapse (a few puffs) or relapse). Self report on abstinence was collected at visits just before carbon monoxide levels were measured to avoid any influence on self report from the carbon 
monoxide results. Secondary outcome measures for the newborn included head circumference $(\mathrm{cm})$, length $(\mathrm{cm})$, Apgar score at five minutes, and intrauterine growth restriction. We calculated intrauterine growth restriction according to AUDIPOG (Association des Utilisateurs de Dossiers Informatisés en Pédiatrie, Obstétrique et Gynécologie, www.audipog.net/ module_ligne.php), a national network of intrauterine growth data. ${ }^{32}$ This calculation includes the mother's body mass index before pregnancy, the child's sex, birth rank, and gestational age at birth..$^{32-35}$ We defined intrauterine growth restriction as less than the 10th centile of normalised AUDIPOG data.

At each visit we assessed the number of cigarettes smoked, carbon monoxide level in expired air, craving for tobacco, withdrawal symptoms, body weight, and sitting blood pressure. Because of the relatively large day to day fluctuation of cigarette consumption among pregnant smokers ${ }^{3637}$ we recorded cigarette consumption during the past seven days and not number of cigarettes consumed daily. We assessed craving using the 12 item French tobacco craving questionnaire (FTCQ-12) ) $^{38}$ and the French version of the Minnesota nicotine withdrawal scale. ${ }^{39}$ The FTCQ-12 is a valid and reliable self report instrument that assesses four dimensions of tobacco craving: emotionality, expectancy, compulsivity, and purposefulness. Cronbach's $\alpha$ coefficient was 0.84 for emotionality, 0.76 for expectancy, 0.66 for compulsivity, and 0.63 for purposefulness. ${ }^{38}$ Items are rated on a 1 to 7 scale (strongly disagree to strongly agree). To reduce acquiescence, we reverse keyed four items. During data analysis, we inverted raw scores on the reverse keyed items. We calculated scores for tobacco craving by summing item scores for each dimension. For FTCQ-12 we analysed the sum of all dimension scores (range 12-84) and for the Minnesota nicotine withdrawal scale the sum of all items (range 0-32).

Self reported compliance was based on how many patches (15 $\mathrm{mg}$ or $10 \mathrm{mg}$ patch) participants reported using since the last visit and how many patches $(15 \mathrm{mg}$ or $10 \mathrm{mg}$ ) participants brought to their current visit. We subtracted the number of patches participants self reported using since the last visit from that of the prescription/delivery at the previous visit and expressed this as the percentage of the prescribed dose. Compliance was recorded among 307 (76\%) participants at 1016 visits. In accordance with the research protocol, we counted patches used by number of blister packs returned by participants at their current visit, but this was impractical; in one centre all returned patches were lost and two thirds of the women did not return blister packs of used or unused patches. Overall, only one third of delivered patches could be counted for compliance in both the placebo and the nicotine patch groups.

\section{Assessment of safety}

The data safety monitoring board comprised three members with specific expertise in drug treatments in pregnancy. They were independent of the trial and each year examined, while grouping was coded, serious adverse events and non-serious adverse effects and decided about the continuation of the study.

\section{Data analysis}

We analysed data on an intention to treat basis. The intention to treat population was defined as all pregnant smokers having received a randomisation number and a prescription. We considered those participants who missed a visit as smokers. Smoking (lapse or relapse) was not a reason for discontinuation. We contacted those women who missed a visit by telephone; missed visits were not a criterion for discontinuation. The women were strongly encouraged to stay in the trial up to delivery. We defined the end of follow-up as end of pregnancy: delivery or other (for example, miscarriage). We hypothesised that even a short period of smoking abstinence could lead to improved birth weight. Therefore we made every effort to track down all the newborn babies of the randomised women.

Data were analysed blinded to treatment. Once the data analyses had been completed, we opened the sealed envelope containing each group's code. The population for the safety analysis was the same as that for the intention to treat population. No intermediate analysis was planned. Data from the post-delivery follow-up visit were not analysed because attendance was low $(n=86)$, and the visit's date ranged from seven to 425 days, thereby making a comparison of the infants' weight inadequate.

To obtain the nicotine substitution rate we divided the saliva cotinine concentration at visits 2 and 4 by that of the baseline concentration (when smoking). Overall, at these visits 162 and 103 participants in the nicotine patch group and 140 and 79 in the placebo patch group contributed to the calculation of the nicotine substitution rate.

We compared the baseline characteristics and delivery outcomes of the participants using Fisher's exact test for qualitative variables and the Mann-Whitney U test for quantitative variables. Complete abstinence rates were compared using Fisher's exact test. We used the log rank test to compare the time to lapse or relapse. The exact date of the relapse after quit date was not collected because of the uncertainty of recall and the lack of biochemical measure (carbon monoxide level in expired air); the date of lapse or relapse was defined as the date of the visit at which the non-abstinence was first ascertained. Using a mixed effect logistic model for longitudinal data we compared the point prevalence abstinence rate. To take into account the clustering of outcomes (twin pregnancies), we compared birth outcome measures using a linear mixed model for quantitative variables and a generalised linear model with a logit link function for qualitative variables. To test whether changes over time of blood pressure, weight, craving tobacco, withdrawal symptoms, number of cigarettes smoked, carbon monoxide level in expired air, and saliva cotinine concentration were different for the two treatment groups, we used a linear mixed model with time, group, and their interaction as fixed effects. Data are presented as medians and interquartile ranges or means and standard deviations or standard errors for estimated means. All analyses were performed with the SAS software version 8.2 (SAS Institute, Cary, NC).

\section{Results}

The study was conducted between October 2007 and January 2013. Of 476 pregnant smokers screened, 73 were excluded for various reasons. Overall, 203 women were randomised to receive nicotine patches and 199 to receive placebo patches (fig $1 \Downarrow$ ); 92 and 113 participants, respectively, withdrew from the study. One hundred and fifteen women gave birth before the last visit in each group (nicotine patch group 57\%, placebo patch group $58 \%$ ), and in both groups 192 live births could be analysed for birth weight. The baseline characteristics of the participants did not differ (table $1 \Downarrow$ ).

A target quit date was established in less than 24 hours in $83 \%$ of the women randomised to receive the nicotine patch and in $85 \%$ randomised to receive the placebo patch, and in $11 \%$ and $14 \%$, respectively, between days 2 and 7 . The initial patch dose based on saliva cotinine concentration was $15 \mathrm{mg}$ in both groups (table 1). The mean daily prescription dose for the whole treatment period was $18 \mathrm{mg}(\mathrm{SD} 6.8 \mathrm{mg})$ in the nicotine patch 
group and $19.2 \mathrm{mg}(6.9 \mathrm{mg})$ in the placebo patch group $(\mathrm{P}=0.11)$. In both groups, $25 \%$ of the participants were prescribed 25-30 $\mathrm{mg}$ patches per day. The median length of the prescription was 105 days (interquartile range $35-175)$ in the nicotine patch group and 70 (35-175) days in the placebo patch group $(\mathrm{P}=0.03)$.

In total, 21722 nicotine patches and 19702 placebo patches were issued to the participants. Compliance could be assessed in 164/203 (81\%) women in the nicotine patch group and $143 / 199(72 \%)$ in the placebo patch group. The median self reported compliance rate was $85 \%$ (interquartile range $56-99 \%$ ) in the nicotine patch group and $83 \%(56-95 \%)$ in the placebo patch group $(\mathrm{P}=0.39)$.

In the nicotine patch group the mean saliva cotinine concentrations were $119 \mu \mathrm{g} / \mathrm{L}$ (SE 1.05) when smoking, 108 (1.1) $\mu \mathrm{g} / \mathrm{L}$ at two weeks after quit date, and $80(1.1) \mu \mathrm{g} / \mathrm{L}$ at eight weeks after quit date. The respective values in the placebo patch group were 127 (1.1) $\mu \mathrm{g} / \mathrm{L}, 67$ (1.1) $\mu \mathrm{g} / \mathrm{L}$, and 63 (1.1) $\mu \mathrm{g} / \mathrm{L}$ (group by time interaction $\mathrm{P}<0.001$ ). The corresponding nicotine substitution rates were $96 \%$ (interquartile range $68-129 \%)$ and $80 \%$ (57-121\%) in the nicotine patch group and significantly lower in the placebo patch group: $70 \%$ (35-103\%) and $68 \%(22-104 \%)(\mathrm{P}<0.001)$. In the nicotine patch group women who abstained from smoking had lower nicotine substitution rates than women who lapsed or relapsed: at two weeks after quit date (abstinent women 54\% (39-83\%), non-abstinent women $100 \%(74-135 \%), \mathrm{P}=0.0006)$ and at eight weeks after quit date (34\% (15-65\%) and 89\% (89-127\%), $\mathrm{P}=0.0003)$ (retrospective analysis).

\section{Smoking abstinence}

Despite the higher saliva cotinine levels and nicotine substitution rates in the nicotine patch group, the continuous, complete abstinence rate was low and similar in both groups: $11(5.5 \%)$ women in the nicotine patch group and $10(5.1 \%)$ in the placebo patch group (odds ratio $1.08,95 \%$ confidence interval 0.45 to 2.60) remained abstinent from quit date up to the last visit before delivery $(\mathrm{P}=0.87)$. By week 2 after target quit day, $62 \%$ of the women had relapsed; the median time to the first cigarette smoked after target quit day was 15 days in both groups (fig $2 \Downarrow$ ). The point prevalence abstinence rate was low, between $8 \%$ and $12.5 \%$ in the nicotine patch group and between $8 \%$ and $9.5 \%$ in the placebo patch group (fig $3 \Downarrow$ ). There was no significant group (treatment) effect $(\mathrm{P}=0.98)$ or time by group interaction $(\mathrm{P}=0.42)$. To determine whether treatment compliance influenced point prevalence abstinence, we also included the previous week's compliance in this analysis (retrospective analysis). The effect of compliance was not significant $(\mathrm{P}=0.17)$ and there was no compliance by group interaction $(\mathrm{P}=0.81)$. The $\mathrm{P}$ value of the group effect remained large $(\mathrm{P}=0.91)$.

Ninety six women in the nicotine patch group and 76 in the placebo patch group completed all visits. Even in this population of completers the abstinence rate was low: $11.5 \%$ and $13.2 \%$ (odds ratio $1.17,95 \%$ confidence interval 0.47 to $2.92, \mathrm{P}=0.74$, retrospective analysis).

Overall, $42 \%$ of women in the nicotine patch group and $37 \%$ in the placebo patch group reduced their cigarette consumption by at least $50 \%$ between the first and last visit $(\mathrm{P}=0.31)$. Cigarettes consumed daily and carbon monoxide levels in expired air decreased in both groups but without a statistically significant difference (time by group interaction $\mathrm{P}=0.498$ and $\mathrm{P}=0.23$, respectively, table $2 \Downarrow$ ). Craving for tobacco, as assessed by the FTCQ-12, showed a progressive decline but no difference between the treatments (time by group interaction $\mathrm{P}=0.351$ ).
The total score for withdrawal symptoms (Minnesota nicotine withdrawal scale) decreased in both groups; there was a tendency for a higher reduction in the nicotine patch group than in the placebo patch group (treatment by time interaction $\mathrm{P}=0.0594$ ). However, among women with complete, continuous abstinence, both craving for tobacco and withdrawal symptoms decreased significantly more $(\mathrm{P}<0.001)$ than among women without continuous abstinence, but this difference was independent of treatments.

Body weight increased in both groups with no difference between the groups (group by time interaction $\mathrm{P}=0.361$, table 2).

\section{Birth and delivery outcomes}

Birth weight, z score, birthweight centile, head circumference, and the number of newborns with fetal growth restriction or with low birth weight were similar (table $3 \Downarrow$ ). Delivery outcomes did not differ (table 3). Results did not change when data were analysed without the twin pregnancies. Analysis restricted to completers' data also showed no difference between the groups (table $4 \Downarrow$ ).

In a multivariate analysis (retrospective analysis) we included all known potential predictors of birth weight (sex, gestational age at birth, history of premature birth, history of fetal growth restriction, twin pregnancy, birth rank, maternal body mass index before pregnancy, maternal age) along with treatment group. Using forward selection, shorter gestational age (estimate 200.42 (SE 9.85), $\mathrm{P}<0.001$ ), history of fetal growth restriction (212.63 (SE 66.01), $\mathrm{P}=0.0014$ ), female sex (107.88 (SE 41.56), $\mathrm{P}=0.0098)$, and lower body mass index before pregnancy $(7.63$ (SE 3.78), $\mathrm{P}=0.044$ ) were significantly associated with lower birth weight, but not treatment group.

Importantly, the newborns of the 21 pregnant women who were completely abstinent from quit date until the predelivery visit had a significantly higher birth weight (3364 g (SE 129) v 3021 (SE 32) g, $\mathrm{P}=0.01)$, $\mathrm{z}$ score $(0.12$ (SE 0.24) $v-0.48$ (SE 0.06), $\mathrm{P}=0.02)$, and weight centile (52.3 (SE 6.1) v 38.4 (SE 1.5), $\mathrm{P}=0.03)$ than the newborns $(\mathrm{n}=363)$ of women who were not continuously abstinent from quit date until delivery, thus showing the benefit of complete abstinence from smoking.

\section{Safety}

Systolic blood pressure moderately increased during pregnancy but without a between group difference. Diastolic blood pressure showed a significant time by group interaction $(\mathrm{P}=0.01)$; the increase in diastolic blood pressure was $0.02 \mathrm{~mm} \mathrm{Hg}$ per day (SE 0.009) in the nicotine patch group compared with no increase in the placebo patch group (fig $4 \Downarrow$ ). For example, at the last predelivery visit the median diastolic blood pressure was $70 \mathrm{~mm} \mathrm{Hg}$ (interquartile range 60-80) in the nicotine patch group and 62 (60-70) $\mathrm{mm} \mathrm{Hg}$ in the placebo patch group $(\mathrm{P}=0.02)$.

In total, 310 (nicotine patch group) and 253 (placebo patch group) ultrasound examination reports were available; abnormalities were observed in $18(5.8 \%)$ in the nicotine patch group and $14(5.5 \%)$ in the placebo patch group.

The number of serious adverse events was similar but more non-gynaecological-obstetric adverse effects were recorded in the nicotine patch group than in the placebo patch group (table $5 \Downarrow$ ). This mainly concerned skin reactions. 


\section{Discussion}

The current study shows that even a relatively high daily dose of nicotine, adjusted for baseline saliva cotinine levels and administered with a relatively high self reported compliance rate for a median of 105 days during the second and third trimester did not increase abstinence rates. The complete abstinence rate from quit date up to end of pregnancy was low (5.5\% and $5.1 \%$ ), and this was lower than the $21 \%$ and $19 \%$ (relative risk $1.1 \%, 95 \%$ confidence interval $0.7 \%$ to $1.8 \%$ ) found in the most similarly designed previous study, ${ }^{12}$ but with a substantially shorter exposure. The nicotine substitution rate in the nicotine patch group showed that abstinence was unrelated to the level of nicotine substitution, suggesting that factors other than nicotine replacement may determine abstinence in pregnant smokers.

A probable consequence of the lack of efficacy for abstinence observed in this study is that compared with placebo the transdermal nicotine patch did not increase birth weight and other birth characteristics. The nicotine patch did not significantly reduce craving for tobacco, withdrawal symptoms, and number of cigarettes smoked.

The point difference in the frequency of at least one serious adverse event among mothers was $4 \%$ (table 5). A significant difference (at $\mathrm{P} \leq 0.05$ ) would have required 882 women per group, therefore we cannot draw firm conclusions about differences in serious adverse events. More

non-gynaecological-obstetric adverse effects were observed with use of the nicotine patch, with the greatest difference for skin reactions.

Diastolic blood pressure increased significantly in the nicotine patch group compared with placebo patch group. Previous studies on NRT in pregnant smokers did not report on blood pressure so this should be considered as a preliminary finding that needs confirmation. However, nicotine may increase diastolic blood pressure, ${ }^{41}$ and this effect on blood pressure is mediated by peripheral nicotinic receptors in the sympathetic nervous system. ${ }^{42}$

The median length of prescription was longer in the nicotine patch group than in the placebo patch group. This could be considered as an intermediate sign of efficacy if it paralleled the main or secondary outcomes, which was not the case. However, because more non-serious adverse reactions occurred in the nicotine patch group, it is likely that the longer median length of prescription (visit attendance) in that group is a consequence of perception of non-serious adverse reactions with the active drug treatment-that is, the presence of non-serious adverse reactions may have suggested to participants that they were receiving the active treatment and might have increased attendance.

Most of the relapses occurred by week 2 after quit date. The dose adjustment schedule aimed, in case of insufficient initial tailoring, to rectify the initial dose of nicotine if the therapeutic response was insufficient (relapse), either by increasing the dose (to increase the likelihood of abstinence) or maintaining it (to prevent relapse), both aiming to enhance abstinence rates in the following months. However, even this schedule did not increase the efficacy of the nicotine patches.

\section{Strengths and weaknesses of this study}

The strengths of this study include the individualised adjustment of daily nicotine dose according to saliva cotinine levels while smoking and potentially resulting in a close to $100 \%$ nicotine substitution rate. The formula we used allowed concomitant cigarette use to be compensated for by increasing the daily dose of nicotine. The adjustment might also have avoided under-dosing or overdosing. Compared with previous studies ${ }^{12-19}$ the duration of treatment was longer and higher daily doses of nicotine were administered, leading to an overall higher exposure to nicotine. The self reported compliance rate was higher than previously reported ${ }^{12-19}$ probably because of the relatively frequent face to face visits. We used a licenced nicotine patch, a warranty of validated bioavailabilty, which allowed the findings of the nicotine patches to be generalised to clinical practice. The placebo patches were manufactured by the same company, with specific quality control guidelines to ensure double blinding. The study, unlike previous smoking cessation trials in pregnant smokers, reports on craving for tobacco, withdrawal symptoms, and blood pressure.

Study limitations were that treatment started only after the end of the first trimester; if effective, starting treatment earlier may have resulted in better outcomes, as smoking cessation at less than 15 weeks' gestation provides similar birth outcomes to those in non-smokers. ${ }^{43}$ However, studies in animals have shown that nicotine is a developmental neurotoxicant, particularly during the early phase of pregnancy, ${ }^{44}$ and owing to a lack of safety data in humans, we avoided nicotine being administered during the first trimester. Participants were women seeking smoking cessation treatment in pregnancy, who consumed at least five cigarettes a day; therefore the results are difficult to generalise to other pregnant smokers. The trial's population was a highly tobacco dependent group. Generalisability of the results to a less dependent population of pregnant smokers should be done with caution.

The observed difference in the rate of complete abstinence (nicotine patch 5.5\%, placebo patch 5.1\%) was less than planned and cannot be considered as clinically significant; 49242 pregnant smokers in each group would be needed to provide a significant difference. Moreover, the point prevalence rate was also low and far from a statistically significant difference. No effect of nicotine patch in improving craving or withdrawal symptoms was observed. Because between intervention differences occur mainly during the first month, in randomised, controlled smoking cessations studies using NRT, ${ }^{23}$ lack of difference in the time to relapse during the early phase of the trial also confirms the lack of efficacy. We would have needed to randomise 1939 women by group for the observed $50 \mathrm{~g}$ difference in birth weight to become significantly different.

Our primary smoking cessation outcome was stringent and we assumed that women who missed a visit were smoking. This definition might have reduced the overall abstinence rate in both groups. However, in this sample no women who missed one appointment were abstinent at other visits.

\section{Implications for clinicians and policy makers and unanswered questions and future research}

\section{Efficacy}

Because NRT were licenced for smoking cessation in France in 1997, the current trial was conducted to confirm their hypothesised efficacy. One well powered but short exposure study ${ }^{19}$ and meta-analyse ${ }^{17}{ }^{18}$ of previous trials using standard NRT doses for a shorter period than the present study concluded that NRTs are not effective in pregnant smokers.

The current findings show that relatively long and high dose exposure using an individualised dosage regimen did not increase complete or point prevalence abstinence rates or time to relapse and thus confirms the lack of efficacy of NRT in 
pregnant smokers and consequently the lack of improvement of birth characteristics. As in several previous studies, craving for tobacco declined progressively ${ }^{27-47}$ but without a difference between the groups. These are disappointing results and should encourage efforts to evaluate new approaches that are both drug and non-drug related. In the absence of evidence based drug interventions, behavioural support remains the core intervention to help pregnant smokers to quit.

Uncertainty exists about whether results would be different in a less dependent population of pregnant smokers, and whether other forms of NRT, such as transdermal NRT started before or during the first weeks of pregnancy, would yield superior results. Data from 3880 pregnant smokers attending stop smoking services in England have shown that two weeks' abstinence during four weeks of treatment using combination NRT was higher than with no treatment or with single NRT, single NRT being no different from no treatment; however, the odds of success declined each month. ${ }^{48}$ The promising efficacy of combination NRT should be assessed in controlled trials, along with pregnancy and perinatal outcomes.

\section{Safety}

The current study shows that the nicotine patch may increase diastolic blood pressure at the end of pregnancy, which may potentially lead to unfavourable pregnancy outcomes. A median $8 \mathrm{~mm} \mathrm{Hg}$ end of pregnancy difference in otherwise healthy women can be considered clinically important. Transposing this to the large population of pregnant smokers using nicotine patches, these data suggest that diastolic blood pressure can be a clinical concern. Future studies should confirm or refute this finding. Fewer than 2000 pregnant smokers were exposed to NRT in randomised, controlled smoking cessation studies. This number is too low to make a judgment about the safety of NRT. Future studies should monitor the safety of NRT in pregnancy.

Preliminary results of this study were presented as an oral presentation at the Society for Research on Nicotine and Tobacco 2013 international meeting, 13-16 March, Boston, USA.

All authors are employees (public servants) of Assistance publique-Hôpitaux de Paris. IB is also an employee of Université P \& M Curie-Faculté de medicine, Paris.

We thank the following investigators for their contributions: Marion Adler; Michel Artus; Frédérique Aubourg; Christine Beillard; Lydie Bernhard (psychologist); Fabienne Bottet; Pierre Boulot; Martine Breton, (midwife); Christine Camus; Michel Collet; Michel Delcroix; Sophie Forest (midwife); Dominique Fourez (nurse); Nathalie Hochedé (midwife); Sophie Kalamarides; Catherine Marçais-Espiand (midwife); Brigitte Mollé-Guilliani (midwife); Marie-Christine Pavia (midwife); Fabrice Pierre; Stephanie Pozzi-Gaudin; Laurette Schultz-Martini; Rémi Targhetta; Van Trung To; Corinne Vannimenus; Catherine Wiard. We thank Gunnar Gustavsson and McNeil-Johnson \& Johnson for providing the nicotine and placebo patches free of charge; Shoreh Azimi, research coordinator, for her assistance with the study; Nicolas Rodon for creating and handling the electronic case report form; and the members of the drug safety monitoring board: Corinne Alberti, Elisabeth Elefant, and François Goffinet.

Contributors: All authors had full access to the data, contributed to the data analysis and interpretation of the results, and reviewed and approved the final manuscript. IB conceived and developed the study design, led the data analysis, and wrote the paper. He had final responsibility to submit it for publication and is the guarantor. The views and opinions expressed in this article are those of the authors and do not necessarily reflect those of the French Ministry of Health.
Funding: This study was funded by the Ministry of Health, France (grant No MA05 00150) and co-sponsored by Assistance publique-Hôpitaux de Paris (P060604). The Ministry of Health and Assistance publique-Hôpitaux de Paris had no role in the design and conduct of the study; the collection, conduct, analysis, and interpretation of the data; or the preparation, review, or approval of the manuscript.

Competing interests: All authors have completed the ICMJE uniform disclosure form at www.icmje.org/coi_disclosure.pdf (available on request from the corresponding author) and declare that: none had support of any kind for the submitted work; IB has served as a paid consultant for Pfizer, Novartis, and Ethypharm in the past three years; none of the authors' spouses, partners, or children has financial relationships that may be relevant to the submitted work; and none of the authors has non-financial interests that may be relevant to the submitted work.

Ethical approval: The research protocol was approved by the ethics committee (Comité de Protection des personnes) of the Pitié-Salpêtrière Hospital on 26 March 2007.

Data sharing: Assistance publique-Hôpitaux de Paris, owner of the Study of Nicotine Patch in Pregnancy (SNIPP) database, is willing to examine all requests for thetechnical appendix, statistical code, and dataset on an individual basis after a period of three years from the date of this publication. Access to data will be formalised on a contractual basis with Assistance publique-Hôpitaux de Paris. The research protocol in French is available on request from the first author (ivan.berlin@psl.aphp.fr).

Transparency: The lead author (the manuscript's guarantor) affirms that the manuscript is an honest, accurate, and transparent account of the study being reported; that no important aspects of the study have been omitted; and that any discrepancies from the study as planned (and, if relevant, registered) have been explained.

1 Surgeon General. A report of the surgeon general: how tobacco smoke causes disease, chapter 8: reproductive and developmental effects. 2010. 2013. www.surgeongeneral. gov/library/reports/tobaccosmoke/chapter8.pdf.

2 Buka SL, Shenassa ED, Niaura R. Elevated risk of tobacco dependence among offspring of mothers who smoked during pregnancy: a 30-year prospective study. Am J Psychiatry 2003;160:1978-84.

3 Ekblad M, Gissler M, Lehtonen L, Korkeila J. Prenatal smoking exposure and the risk of psychiatric morbidity into young adulthood. Arch Gen Psychiatry 2010;67:841-9.

4 Burke $\mathrm{H}$, Leonardi-Bee J, Hashim A, Pine-Abata H, chen Y, Cook DG, et al. Prenatal and passive smoke exposure and incidence of asthma and wheeze: systematic review and meta-analysis. Pediatrics 2012;129:735-44

5 Lumley J, Chamberlain C, Dowswell T, Oliver S, Oakley L, Watson L. Interventions for promoting smoking cessation during pregnancy. Cochrane Database Syst Rev 2009;3:CD001055

6 Benowitz NL, Dempsey DA, Goldenberg RL, Hughes JR, Dolan-Mullen P, Ogburn PL, et al. The use of pharmacotherapies for smoking cessation during pregnancy. Tob Control 2000;9(Suppl 3):III91-4.

7 Coleman T, Britton J, Thornton J. Nicotine replacement therapy in pregnancy. BMJ 2004;328:965-6.

8 Oncken CA, Kranzler HR. What do we know about the role of pharmacotherapy for smoking cessation before or during pregnancy. Nicotine Tob Res 2009;11:1265-73.

9 Agence national de sécurité du médicament et des produits de santé, ANSM. Traitement de substituts nicotiniques (TSN) et femmes enceintes. 6 Oct 2006. 2013. [In French.] http: //ansm.sante.fr/S-informer/Presse-Communiques-Points-presse/Traitements-de-SubstitutsNicotiniques-TSN-et-femmes-enceintes/\%28language\%29/fre-FR.

10 National Institute for Health and Care Excellence. Recommendation 5 Use of NRT and other pharmacological support. 2013. http://publications.nice.org.uk/quitting-smoking-inpregnancy-and-following-childbirth-ph26/recommendations\#recommendation-5-use-ofnrt-and-other-pharmacological-support.

11 US Department of Health and Human Services. Treating tobacco use and dependence. Clinical practice guideline, 2008.

12 Wisborg K, Henriksen TB, Jespersen LB, Secher NJ. Nicotine patches for pregnant smokers: a randomized controlled study. Obstet Gynecol 2000;96:967-71.

13 Kapur B, Hackman R, Selby P, Klein J, Koren G. Randomized, double-blind, placebo-controlled trial of nicotine replacement therapy in pregnancy. Curr Ther Res Clin Exp 2001;62:274-8

14 Hotham ED, Gilbert AL, Atkinson ER. A randomised-controlled pilot study using nicotine patches with pregnant women. Addict Behav 2005;31:641-8.

15 Oncken C, Dornelas E, Greene J, Sankey H, Glasmann A, Feinn R, et al. Nicotine gum for pregnant smokers: a randomized controlled trial. Obstet Gynecol 2008:112:859-67.

16 Pollak KI, Oncken CA, Lipkus IM, Lyna P, Swamy GK, Pletsch PK, et al. Nicotine replacement and behavioral therapy for smoking cessation in pregnancy. Am J Prev Med 2007;33:297-305.

17 Coleman T, Chamberlain C, Cooper S, Leonardi-Bee J. Efficacy and safety of nicotine replacement therapy for smoking cessation in pregnancy: systematic review and meta-analysis. Addiction 2011;106:52-61. 


\section{What is already known on this topic}

Smoking during pregnancy increases the risk of adverse pregnancy and birth outcomes

Guidelines suggest adding nicotine replacement therapies (NTR) to behavioural smoking cessation interventions in pregnant smokers because of their excellent safety profile and proved efficacy in other populations of smokers

Evidence about the efficacy of NTR in pregnant smokers at the level of both maternal abstinence and birth weight is not conclusive

\section{What this study adds}

Compared with placebo and despite individual dose adjustment, longer treatment duration, higher daily nicotine dose than previously used, nicotine patches did not increase smoking cessation rate or birth weight

Diastolic blood pressure was higher with the nicotine patch than with placebo, suggesting that further studies with nicotine in pregnant smokers should control for blood pressure

18 Coleman T, Chamberlain C, Davey MA, Cooper SE, Leonardi-Bee J. Pharmacologica interventions for promoting smoking cessation during pregnancy. Cochrane Database Syst Rev 2012;9:CD010078.

19 Coleman T, Cooper S, Thornton JG, Grainge MJ, Watts K, Britton J, et al. Smoking, Nicotine, and Pregnancy (SNAP) Trial Team. A randomized trial of nicotine-replacement therapy patches in pregnancy. N Engl J Med 2012;366:808-18.

20 Rebagliato M, Bolúmar F, Florey C, Jarvis MJ, Pérez-Hoyos S, Hernández-Aguado I, et al. Variations in cotinine levels in smokers during and after pregnancy. Am J Obstet Gynecol 1998;178:568-71.

21 Dempsey D, Jacob P 3rd, Benowitz NL. Accelerated metabolism of nicotine and cotinine in pregnant smokers. J Pharmacol Exp Ther 2002;301:594-8.

22 Oncken C. Nicotine replacement for smoking cessation during pregnancy. N Engl J Med 2012;366:846-7.

23 Medioni J, Berlin I, Mallet A. Increased risk of relapse after stopping nicotine replacemen therapies: a mathematical modelling approach. Addiction 2005;100:247-54.

24 Benowitz NL, Jacob P 3rd. Metabolism of nicotine to cotinine studied by a dual stable isotope method. Clin Pharmacol Ther 1994;56:483-93.

25 Jarvis MJ, Boreham R, Primatesta P, Feyerabend C, Bryant A. Nicotine yield from machine-smoked cigarettes and nicotine intakes in smokers: evidence from a representative population survey. J Natl Cancer Inst 2001;93:134-8.

26 Benowitz NL, Jacob P 3rd, Herrera B. Nicotine intake and dose-response when smoking reduced-nicotine content cigarettes. Clin Pharmacol Ther 2006;80:703-14.

27 Berlin I, Jacob N, Coudert M, Perriot J, Schultz L, Rodon N. Adjustment of nicotine replacement therapies according to saliva cotinine concentration: the ADONIS* trial-a randomized study in smokers with medical comorbidities. Addiction 2011:106:833-43.

28 Agence nationale d'accréditation et d'évaluation en santé (ANAES): conférence de consensus. Grossesse et tabac. Texte des recommandations. 2004. www.has-sante.fr/ portail/upload/docs/application/pdf/Grossesse_tabac_long.pdf.

29 Solomon L, Quinn V. Spontaneous quitting: self-initiated smoking cessation in early pregnancy. Nicotine Tob Res 2004;6(Suppl 2):S203-16.

30 Li CQ, Windsor RA, Perkins L, Goldenberg RL, Lowe JB. The impact on infant birth weight and gestational age of cotinine-validated smoking reduction during pregnancy. JAMA 1993;269:1519-24

31 Benjamin-Garner R, Stotts A. Impact of smoking exposure change on infant birth weight among a cohort of women in a prenatal smoking cessation study. Nicotine Tob Res 2013;15:685-92.

32 Mamelle N, Munoz F, Grandjean H pour le groupe de travail AUDIPOG. Croissance fœtale à partir de l'étude AUDIPOG. I. Etablissement de courbes de références. J Gynecol Obstet Biol Reprod 1996;25:61-70.

33 Mamelle N, Munoz F, Martin JL, Laumon B, Grandjean $\mathrm{H}$ pour le groupe de travail AUDIPOG. Croissance fœtale à partir de l'étude AUDIPOG. II. Application au diagnostic de retard de croissance intra-utérin. J Gynecol Obstet Biol Reprod 1996;25:71-7.

34 Gardosi J, Chang A, Kalyan B, Sahota D, Symonds EM. Customised antenatal growth charts. Lancet 1992;339:283-7.
35 Figueras F, Gardosi J. Intrauterine growth restrictions: new concepts in antenatal surveillance, diagnosis, and management. Am J Obstet Gynecol 2011;204:288-300.

36 Pickett KE, Wakschlag LS, Dai L, Leventhal BL. Fluctuations of maternal smoking during pregnancy. Obstet Gynecol 2003;101:140-7.

37 Pickett KE, Rathouz PJ, Kasza K, Wakschlag LS, Wright R. Self-reported smoking, cotinine levels, and patterns of smoking in pregnancy. Paediatr Perinat Epidemiol 2005;19:368-76.

38 Berlin I, Singleton EG, Heishman SJ. Validity of the 12-item French version of the Tobacco Craving Questionnaire in treatment-seeking smokers. Nicotine Tob Res 2010;12:500-7.

39 Hughes JR, Hatsukami D. Signs and symptoms of tobacco withdrawal. Arch Gen Psychiatry 1986;43:289-94.

40 Ewing JA. Detecting alcoholism: the CAGE Questionnaire. JAMA 1984;252:1905-7.

41 Soria R, Stapleton JM, Gilson SF, Sampson-Cone A, Henningfield JE, London ED. Subjective and cardiovascular effects of intravenous nicotine in smokers and non-smokers. Psychopharmacology (Berl) 1996;128:221-6.

42 Jutkiewicz EM, Rice KC, Carroll FI, Woods JH. Patterns of nicotinic receptor antagonism II: cardiovascular effects in rats. Drug Alcohol Depend 2013;131:284-97.

43 McCowan LM, Dekker GA, Chan E, Stewart A, Chappell LC, Hunter M, et al; SCOPE consortium. Spontaneous preterm birth and small for gestational age infants in women who stop smoking early in pregnancy: prospective cohort study. BMJ 2009:338:b1081.

44 Slotkin TA. If nicotine is a developmental neurotoxicant in animal studies, dare we recommend nicotine replacement therapy in pregnant women and adolescents? Neurotoxicol Teratol 2008;30:1-19.

45 Dawkins L, Powell JH, Pickering A, Powell J, West R. Patterns of change in withdrawal symptoms, desire to smoke, reward motivation and response inhibition across 3 months of smoking abstinence. Addiction 2009;104:850-8.

46 Herd N, Borland R. The natural history of quitting smoking: findings from the International Tobacco Control (ITC) Four Country Survey. Addiction 2009;104:2075-87.

47 Berlin I, Hu MC, Covey LS, Winhusen T. Attention-deficit/hyperactivity disorder (ADHD) symptoms, craving to smoke, and tobacco withdrawal symptoms in adult smokers with ADHD. Drug Alcohol Depend 2012;124:268-73.

48 Brose LS, McEwen A, West R. Association between nicotine replacement therapy use in pregnancy and smoking cessation. Drug Alcohol Depend 2013;132:660-4.

\section{Accepted: 8 February 2014}

\section{Cite this as: BMJ 2014;348:g1622}

This is an Open Access article distributed in accordance with the Creative Commons Attribution Non Commercial (CC BY-NC 3.0) license, which permits others to distribute, remix, adapt, build upon this work non-commercially, and license their derivative works on different terms, provided the original work is properly cited and the use is non-commercial. See: http://creativecommons.org/licenses/by-nc/3.0/. 


\section{Tables}

\begin{tabular}{|c|c|c|c|c|}
\hline Characteristics & Nicotine patch $(n=203)$ & $\%(95 \% \mathrm{Cl})$ & Placebo patch $(n=199)$ & $\%(95 \% \mathrm{Cl})$ \\
\hline \multicolumn{5}{|l|}{ Personal } \\
\hline Median (interquartile range) age (years) ${ }^{\star}$ & $29.1(25-34)$ & - & $29.4(25-33)$ & - \\
\hline \multicolumn{5}{|l|}{ Professional status: } \\
\hline Employed & 112 & $55.2(48.1$ to 62.1$)$ & 115 & 57.8 (50.6 to 64.7$)$ \\
\hline Housewife & 44 & 21.7 (16.2 to 28$)$ & 45 & 22.6 (17 to 29.1$)$ \\
\hline Unemployed & 45 & $22.2(16.7$ to 28.5$)$ & 38 & $19.0(13.9$ to 25.3$)$ \\
\hline Student & 2 & $1.0(0.1$ to 3.5$)$ & 1 & $0.5(0.01$ to 2.77$)$ \\
\hline \multicolumn{5}{|l|}{ Marital status: } \\
\hline Cohabiting & 150 & 73.9 (67.3 to 79.8$)$ & 148 & 74.4 (67.7 to 80.3$)$ \\
\hline Married & 21 & $10.3(6.5$ to 15.4$)$ & 23 & $11.6(7.5$ to 16.8$)$ \\
\hline Separated & 1 & 0.5 (0.01 to 2.7$)$ & 3 & 1.5 (0.3 to 4.3$)$ \\
\hline Divorced & 1 & 0.5 (0.01 to 2.7$)$ & 3 & 1.5 (0.3 to 4.3$)$ \\
\hline Single & 30 & $14.8(10.2$ to 20.4$)$ & 22 & $11.1(7.1$ to 16.3$)$ \\
\hline \multicolumn{5}{|l|}{ Annual household income $(€)$ : } \\
\hline$<12000$ & 62 & 30.5 (24.3 to 37.4$)$ & 69 & $34.7(28.1$ to 41.7$)$ \\
\hline 12000 to 30000 & 98 & $48.3(41.2$ to 55.4$)$ & 103 & $51.8(44.6$ to 58.9$)$ \\
\hline 30000 to 100000 & 41 & $20.2(14.9$ to 26.4$)$ & 26 & $13.1(8.7$ to 18.6$)$ \\
\hline$>100000$ & 2 & $1.0(0.1$ to 3.5$)$ & 1 & $0.5(0.01$ to 2.77$)$ \\
\hline \multicolumn{5}{|l|}{ Ethnic origin: } \\
\hline European & 194 & 95.6 (92.8 to 98.4$)$ & 191 & 96 (92.2 to 98.3$)$ \\
\hline African & 6 & $3.0(0.6$ to 5.3$)$ & 5 & 2.5 (0.8 to 5.8$)$ \\
\hline Asian & 1 & 0.5 (0.01 to 2.7$)$ & 1 & $0.5(0.01$ to 2.77$)$ \\
\hline Other & 2 & $1.0(0.1$ to 3.5$)$ & 2 & $1.0(0.1$ to 3.58$)$ \\
\hline \multicolumn{5}{|l|}{ Median (interquartile range) blood pressure $(\mathrm{mm} \mathrm{Hg})$ : } \\
\hline Systolic & $110(102-120)$ & - & $110(100-120)$ & - \\
\hline Diastolic & $60(60-70)$ & - & $60(60-70)$ & - \\
\hline \multicolumn{5}{|l|}{ Median (interquartile range) body mass index: } \\
\hline Before pregnancy & $23(20-27)$ & - & $23(20-27)$ & - \\
\hline At randomisation & $24(22-28)$ & - & $24(21-28)$ & - \\
\hline \multicolumn{5}{|l|}{ Obstetrical } \\
\hline Median (interquartile range) gestational age at randomisation (weeks): & $17(15-20)$ & - & $17(15-20)$ & - \\
\hline \multicolumn{5}{|l|}{ Parity } \\
\hline 0 & 66 & 32.5 (26.1 to 39.4$)$ & 46 & 23 (17.5 to 29.6$)$ \\
\hline 1 & 42 & 20.7 (15.3 to 26.9$)$ & 67 & $33.7(27.1$ to 40.7$)$ \\
\hline 2 & 38 & $18.7(13.6$ to 24.8$)$ & 40 & 20.1 (14.8 to 26.4$)$ \\
\hline$\geq 3$ & 57 & 28.1 (22 to 34.8$)$ & 46 & $23.0(17.5$ to 29.6$)$ \\
\hline Median (interquartile range) No of previous pregnancies & $1(0-3)$ & - & $1(1-2)$ & - \\
\hline History of premature delivery & 24 & $11.8(7.7$ to 17.1$)$ & 14 & $7.0(3.5$ to 10.6$)$ \\
\hline History of small for gestational age at birth & 24 & $11.8(7.7$ to 17.1$)$ & 19 & $9.6(5.9$ to 14.5$)$ \\
\hline Maternal disorders before randomisation & 19 & 9.4 (5.7 to 14.2$)$ & 19 & $9.6(5.9$ to 14.5$)$ \\
\hline \multicolumn{5}{|l|}{ Smoking } \\
\hline Median (interquartile range) previous quit attempts ( $\geq 1$ week) & $1(0-2)$ & - & $1(0-2)$ & - \\
\hline Median (interquartile range) age at first cigarette (years) & $15(13-16)$ & - & $14(13-16)$ & - \\
\hline Median (interquartile range) age of regular smoking (years) & $16(15-18)$ & - & $16(14-18)$ & - \\
\hline Median (interquartile range) cigarettes/day & $11(8-15)$ & - & $10(8-15)$ & - \\
\hline
\end{tabular}




\section{Table 1 (continued)}

\section{Characteristics}

Median (interquartile range) carbon monoxide level in expired air (ppm)

Fagerström test for nicotine dependence:

Median (interquartile range) total score (0 to 10)

Nicotine patch $(\mathrm{n}=203)$

$11(7-15)$
$\%(95 \% \mathrm{Cl})$

-
Placebo patch $(\mathrm{n}=199) \quad \%(95 \% \mathrm{Cl})$

$11(7-14)$

\begin{tabular}{|c|c|c|c|c|}
\hline$>60$ & 31 & $15.3(10.6$ to 21$)$ & 20 & $10.0(6.3$ to 15.1$)$ \\
\hline 31 to 60 & 36 & 17.7 (12.7 to 23.7$)$ & 48 & 24.0 (18.4 to 30.7$)$ \\
\hline 6 to 30 & 74 & 36.5 (29.8 to 43.5$)$ & 85 & 43.0 (35.7 to 49.9$)$ \\
\hline$\leq 5$ & 62 & 30.5 (24.3 to 37.4$)$ & 46 & $23.0(17.5$ to 29.6$)$ \\
\hline \multicolumn{5}{|l|}{ No of cigarettes/day: } \\
\hline$\leq 10$ & 88 & 43.4 (36.5 to 50.1$)$ & 92 & $46.2(39.2$ to 53.4$)$ \\
\hline 11 to 20 & 96 & 47.3 (40.3 to 54.4$)$ & 81 & 40.7 (33.9 to 47.5$)$ \\
\hline 21 to 30 & 14 & 6.9 (3.8 to 11.3$)$ & 20 & $10.0(6.3$ to 15.1$)$ \\
\hline$>30$ & 5 & $2.5(0.08$ to 5.7$)$ & 6 & $3.0(1.1$ to 6.5$)$ \\
\hline \multicolumn{5}{|l|}{ CAGE $^{\star}$ questionnaire: } \\
\hline Felt the need to cut down your drinking? & 16 & $7.9(4.6$ to 12.5$)$ & 23 & 11.6 (7.5 to 16.9$)$ \\
\hline Felt annoyed by criticism of your drinking? & 13 & $6.4(3.5$ to 10.7$)$ & 8 & $4.0(1.3$ to 6.8$)$ \\
\hline Had guilty feelings about drinking? & 17 & $8.4(5$ to 13.1$)$ & 15 & 7.6 (4.3 to 12.2$)$ \\
\hline Taken a morning eye opener? & 2 & $1.0(0.1$ to 3.5$)$ & 0 & \\
\hline At least one "Yes" & 22 & $10.8(6.95$ to 15.95$)$ & 28 & 14.1 (9.6 to 19.8$)$ \\
\hline Spouse smokes & 145 & 71.4 (64.7 to 77.5$)$ & 151 & $76.0(69.3$ to 81.7$)$ \\
\hline Other smoker in household & 50 & 24.8 (19 to 31.3 ) & 42 & 21.1 (15.7 to 27.4$)$ \\
\hline Exposure to secondhand smoke at work or leisure & 135 & $66.8(60$ to 73.3$)$ & 129 & $64.8(57.8$ to 71.4$)$ \\
\hline Cannabis use in past 30 days & 4 & $2.0(0.5$ to 5$)$ & 6 & $3.0(1.1$ to 6.5$)$ \\
\hline Prescribed drug use & 59 & 29.1 (23 to 35.8 ) & 67 & 33.7 (27.1 to 40.2$)$ \\
\hline $\begin{array}{l}\text { Median (interquartile range) first nicotine or placebo patch dose per } \\
\text { day }\end{array}$ & $15(10-20)$ & & $15(10-20)$ & \\
\hline
\end{tabular}

$€ 1.00$ (£0.82; €1.40).

${ }^{*}$ Cut-down, Annoyed, Guilt, Eye-opener. ${ }^{40}$ 
Table 2/ Cigarette consumption, carbon monoxide levels in expired air, craving for tobacco, total score of withdrawal symptoms, and maternal body weight (secondary outcomes)

\begin{tabular}{|c|c|c|c|c|c|c|c|}
\hline \multirow[b]{2}{*}{ Intervention by variables } & \multicolumn{7}{|c|}{ Mean (SD) by visit No } \\
\hline & 1: randomisation & $\begin{array}{l}\text { 2: cotinine } \\
\text { sampling }\end{array}$ & $\begin{array}{c}3: \text { dose } \\
\text { adjustment }\end{array}$ & $\begin{array}{l}\text { 4: cotinine } \\
\text { sampling }\end{array}$ & $\begin{array}{c}5: \text { dose } \\
\text { adjustment }\end{array}$ & 6: predelivery & 7: predelivery ${ }^{*}$ \\
\hline \multicolumn{8}{|l|}{$\begin{array}{l}\text { Cigarettes smoked during } \\
\text { past } 7 \text { days: }\end{array}$} \\
\hline Nicotine patch & $77.1(34.4)$ & $34.9(34.9)$ & $30.6(30.6)$ & $33.2(30.6)$ & $32.6(30.9)$ & $28.4(31.5)$ & $21.8(25.8)$ \\
\hline$\%$ decrease & 0 & $44.6(37)$ & $38.6(33)$ & $45(40)$ & $47.6(36)$ & $38.3(37.5)$ & $34.8(39)$ \\
\hline Placebo patch & $78.3(42.8)$ & $41.4(40.1)$ & $41.6(40.7)$ & $41.2(42.5)$ & $35.2(35.8)$ & $30.0(32.4)$ & $39.6(43.2)$ \\
\hline$\%$ decrease & 0 & $55.9(58.5)$ & $56.2(65)$ & $55(54.8)$ & $48.9(60)$ & $41.7(46.2)$ & $55(72.5)$ \\
\hline \multicolumn{8}{|l|}{$\begin{array}{l}\text { Carbon monoxide level in } \\
\text { expired air (ppm): }\end{array}$} \\
\hline Nicotine patch & $12.3(7.1)$ & $7.9(6.4)$ & $7.6(7)$ & $7(6.3)$ & $6.8(5.3)$ & $6.5(5.6)$ & $5.7(5.7)$ \\
\hline Placebo patch & $12.9(8.4)$ & $9.2(9)$ & $8.4(5.7)$ & $8.7(10.2)$ & $7.7(5.6)$ & $6.5(6.6)$ & $6.9(4.7)$ \\
\hline \multicolumn{8}{|l|}{ Craving for tobaccot: } \\
\hline Nicotine patch & $38.2(10.8)$ & $32.4(12.3)$ & $30.1(11.6)$ & $30.3(12.3)$ & $28.3(11.8)$ & $26.4(11.7)$ & $26.5(11.5)$ \\
\hline Placebo patch & $40.5(11.3)$ & $36.2(12.6)$ & $34.5(10.5)$ & $33.5(12.5)$ & $31.2(11.7)$ & $29.7(10.8)$ & $30.5(12.7)$ \\
\hline \multicolumn{8}{|l|}{ Withdrawal symptoms $\ddagger$ : } \\
\hline Nicotine patch & $7.0(4.5)$ & $7.15(5.0)$ & $6.0(4.7)$ & $6.7(5.2)$ & $5.9(4.6)$ & $5.7(4.7)$ & $5.9(5.2)$ \\
\hline Placebo patch & $7.3(4.2)$ & $8.6(4.8)$ & $7.1(3.7)$ & $7.1(4.5)$ & $6.5(4.1)$ & $6.1(4.3)$ & $6.5(5.0)$ \\
\hline \multicolumn{8}{|l|}{ Maternal body weight $(\mathrm{kg})$ : } \\
\hline Nicotine patch & $70.7(15.5)$ & $71.8(15.4)$ & $73.4(15.4)$ & $75.6(15.0)$ & $77.7(15.2)$ & $80.0(15.0)$ & $81.7(15.4)$ \\
\hline Placebo patch & $69.1(14.5)$ & $70.6(14.4)$ & $72.4(14.2)$ & $75.3(13.6)$ & $77.7(13.2)$ & $80.7(13.0)$ & $81.5(11.2)$ \\
\hline \multicolumn{8}{|c|}{$\begin{array}{l}\text { *About one month before delivery. } \\
\text { †12-item French tobacco craving questionnaire. } \\
\text { †French version of Minnesota nicotine withdrawal s }\end{array}$} \\
\hline
\end{tabular}




\begin{tabular}{|c|c|c|c|c|c|}
\hline Outcome measures & Nicotine patch $(n=192)$ & Placebo patch $(n=192)$ & $\begin{array}{l}\text { Difference of least } \\
\text { squares mean values } \\
\qquad(95 \% \mathrm{Cl})\end{array}$ & Odds ratio $(95 \% \mathrm{Cl})$ & $P$ value \\
\hline \multicolumn{6}{|l|}{ Birth outcomes*: } \\
\hline Birth weight $(\mathrm{g})$ & $3065(44)$ & $3015(44)$ & $50(-71.1$ to 172.3$)$ & - & 0.41 \\
\hline z score & $-0.40(0.08)$ & $-0.49(0.08)$ & $0.09(-0.13$ to 0.32$)$ & - & 0.41 \\
\hline Centile† & $40.7(2.1)$ & $37.6(2.1)$ & $3.18(-2.57$ to 8.94$)$ & - & 0.28 \\
\hline Fetal growth restriction†‡ & $0.18(0.19)$ & $0.24(0.17)$ & - & $0.68(0.41$ to 1.11$)$ & 0.12 \\
\hline Low birth weight $(<2500 \mathrm{~g})$ & $0.14(0.21)$ & $0.17(0.19)$ & - & $0.79(0.45$ to 1.39$)$ & 0.42 \\
\hline Length at birth $(\mathrm{cm})$ & $48.3(0.23)$ & $48(0.23)$ & $0.34(-0.31$ to 0.98$)$ & - & 0.31 \\
\hline Head circumference $(\mathrm{cm})$ & $33.7(0.16)$ & $33.9(0.16)$ & $-0.2(-0.63$ to 0.24$)$ & - & 0.37 \\
\hline Cord blood arterial pH & $7.26(0.008)$ & $7.25(0.008)$ & $0.004(-0.02$ to 0.03$)$ & - & 0.75 \\
\hline Apgar score $<10$ at 5 mins & $0.07(0.28)$ & $0.06(0.3)$ & - & $1.2(0.54$ to 2.63$)$ & 0.65 \\
\hline Delivery outcomes§: & $(n=200)$ & $(n=199)$ & & & \\
\hline $\begin{array}{l}\text { Mean (SE) gestational age (weeks } \\
\text { of amenorrhea) }\end{array}$ & $38.3(3.1)$ & 38.5 (2.99) & $-0.22(-0.82$ to 0.38$)$ & - & 0.16 \\
\hline Spontaneous vaginal delivery & $138(69)$ & $147(75)$ & - & $0.76(0.49$ to 1.17$)$ & 0.21 \\
\hline Peridural anaesthesia & $154(78)$ & $135(70)$ & - & 1.57 (0.99 to 2.47$)$ & 0.07 \\
\hline Use of oxytocin & $108(55.7)$ & $103(54.8)$ & - & 1.04 (0.69 to 1.55$)$ & 0.92 \\
\hline Preterm birth & $27(13.5)$ & $26(13)$ & - & 1.04 (0.58 to 1.85$)$ & 0.99 \\
\hline Caesarean section & $51(25.5)$ & $44(22.3)$ & - & $1.21(0.76$ to 1.91$)$ & 0.48 \\
\hline Haemorrhagia at delivery & $10(5.1)$ & $9(4.7)$ & - & $1.08(0.43$ to 2.72$)$ & 0.99 \\
\hline $\begin{array}{l}\text { Transfer to neonatal intensive care } \\
\text { unit }\end{array}$ & $14(7.1)$ & $14(7.2)$ & - & $0.83(0.38$ to 1.85$)$ & 0.99 \\
\hline
\end{tabular}

*Values are estimated least squares means (standard errors). Includes three twins in nicotine patch group and four twins in placebo patch group. †According to AUDIPOG (Association des Utilisateurs de Dossiers Informatisés en Pédiatrie, Obstétrique et Gynécologie) national birth registry network. ${ }^{32} 33$ ‡Birth weight below 10th customised birthweight centile.

$\S$ Values are numbers (percentages) unless stated otherwise. 
Table 4| Birthweight characteristics in completer population ${ }^{\star}$ (exploratory analysis). Data are means (standard error) unless stated otherwise

\begin{tabular}{lccc} 
Characteristics & Nicotine patch $(\mathbf{n}=96)$ & Placebo patch $(\mathbf{n}=\mathbf{7 6})$ & P value \\
Birth weight $(\mathrm{g})$ & $3149(67)$ & $3111(74)$ & 0.71 \\
\hline z score & $-0.24(0.11)$ & $-0.33(0.13)$ & 0.58 \\
\hline Birthweight centile & $44.6(3.14)$ & $42(3.5)$ & 0.58 \\
\hline Fetal growth restrictiont (SE of \%) & $16.3(0.28)$ & $21.1(0.28)$ & 0.43 \\
\hline
\end{tabular}

*Women who completed all visits.

†Birth weight below 10th customised birthweight centile. 


\section{Table 5| Serious adverse events and adverse effects by intervention group}

\section{Adverse events and effects}

No of serious adverse events

At least one serious adverse event:

\begin{tabular}{|c|c|c|}
\hline Mother & 24/203 (12) & $16 / 199(8)$ \\
\hline Newborn/fetus* & $13 / 192(7)$ & $14 / 192(7)$ \\
\hline Fetal: & $n=203$ & $n=203$ \\
\hline Stillbirth & $4(2)$ & $5(2)$ \\
\hline Late miscarriage & $1(0.5)$ & $1(0.5)$ \\
\hline Newborn death at birth & $2(1)$ & 0 \\
\hline Medical abortion & $1(0.5)$ & $1(0.5)$ \\
\hline Total death & $8(4)$ & $7(3)$ \\
\hline Congenital malformation* & $4(2)$ & $6(3)$ \\
\hline Fetal growth restriction ${ }^{*} \dagger$ & $10(5)$ & $9(4)$ \\
\hline Maternalł: & $n=203$ & $n=199$ \\
\hline Pre-eclampsia & $3(1.5)$ & $1(0.5)$ \\
\hline Premature rupture of membranes & $3(1.5)$ & $6(3)$ \\
\hline Threat of premature delivery with hospital stay & $6(3)$ & $5(2.5)$ \\
\hline Renal failure & $3(1.5)$ & 0 \\
\hline No of non-gynaecological-obstetric adverse effects & 121 & 78 \\
\hline Non-gynaecological-obstetric adverse effects§ & $n=203$ & $\mathrm{n}=199$ \\
\hline Headache & $12(6)$ & $9(4.5)$ \\
\hline Skin reaction at patch site & $23(11)$ & $8(4)$ \\
\hline No of gynaecological-obstetric adverse effects & 83 & 84 \\
\hline Gynaecological-obstetric adverse effects $\ddagger$ : & $n=203$ & $n=199$ \\
\hline Gastroesophageal reflux & $8(4)$ & $5(2.5)$ \\
\hline Gestational diabetes & $4(2)$ & $8(2)$ \\
\hline Insomnia & $7(3)$ & $5(2.5)$ \\
\hline Low back pain & $11(5)$ & $7(3.5)$ \\
\hline Metrorrhagia & $2(1)$ & $5(2.5)$ \\
\hline Nausea & $4(2)$ & $3(1.5)$ \\
\hline Perineal or pelvic pain & $3(1.5)$ & $2(1)$ \\
\hline Pyrosis & $4(2)$ & $4(2)$ \\
\hline Threat of premature delivery & $2(1)$ & $2(1)$ \\
\hline Urinary infection & $9(4)$ & $9(4.5)$ \\
\hline Uterus contractions & $5(2.5)$ & $7(3.5)$ \\
\hline Vaginal mycosis & $5(2.5)$ & $7(3.5)$ \\
\hline Vomiting & $5(2.5)$ & $5(2.5)$ \\
\hline
\end{tabular}

*Exclusion of those with fetal death.

†From ultrasonography.

$\ddagger$ With frequency $>1 \%$ in one of the groups.

§With frequency $\geq 5 \%$ in one of the groups.

Nicotine patch ( $n=203$ mothers, $n=203$ newborns) Placebo patch ( $n=199$ mothers, $n=203$ newborns)

60

54

$\stackrel{\text { m }}{s}$

$\stackrel{s}{c}$ 


\section{Figures}

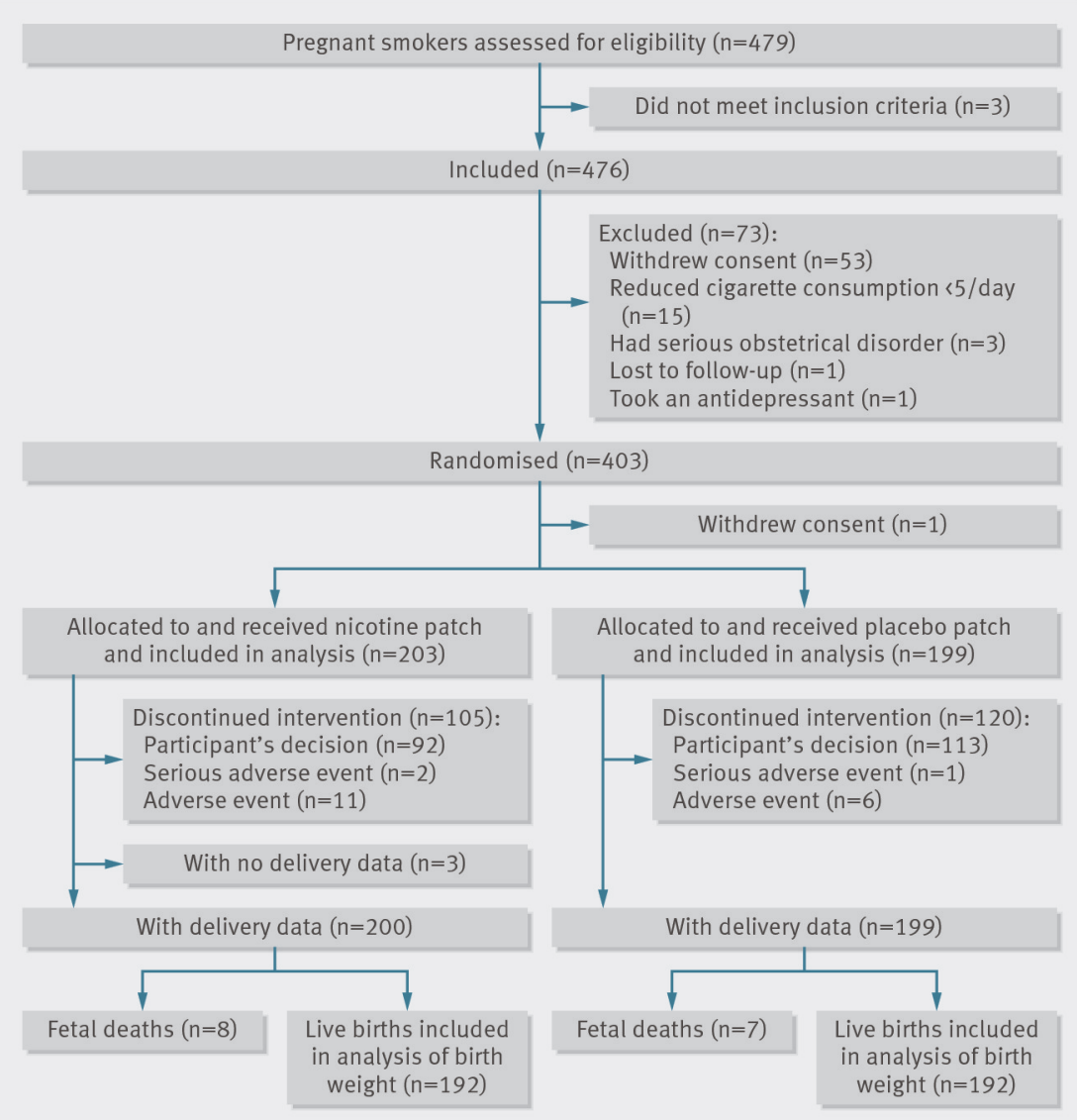

Fig 1 Flow of participants through study

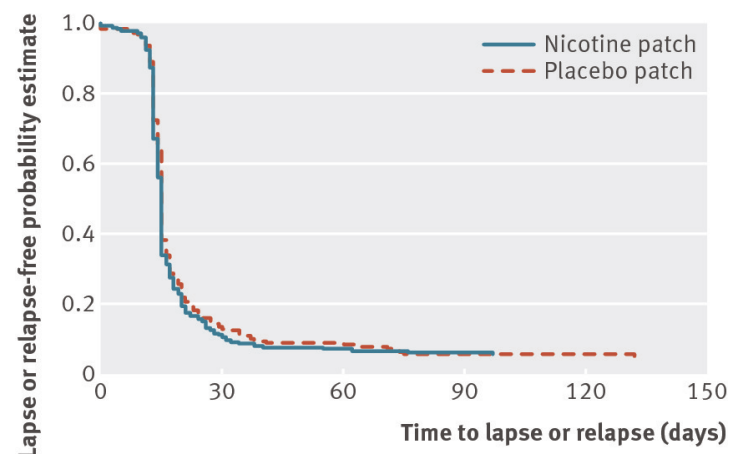

Fig 2 Kaplan-Meier curves of time to first lapse or relapse to smoking. Median time to lapse/relapse: nicotine patch 15 days (interquartile range 13-18); placebo patch 15 (13-20) days, log rank test $\mathrm{P}=0.39$ 


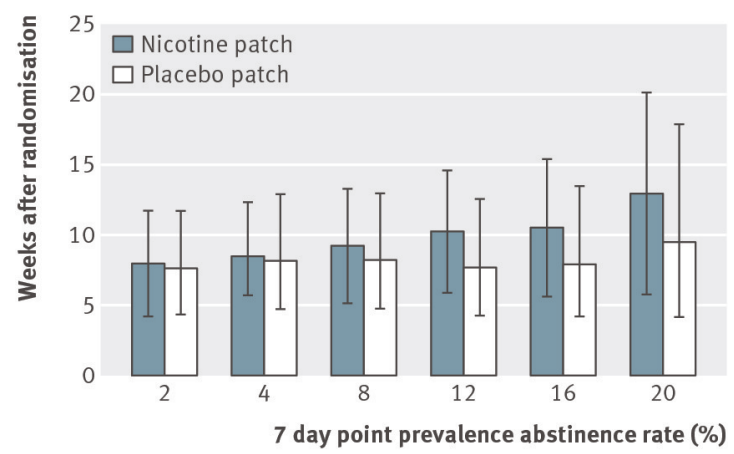

Fig 3 Seven day point prevalence abstinence rate (\%) between week 2 and week 20 visits (last visit before delivery). Bars indicate $95 \%$ confidence intervals

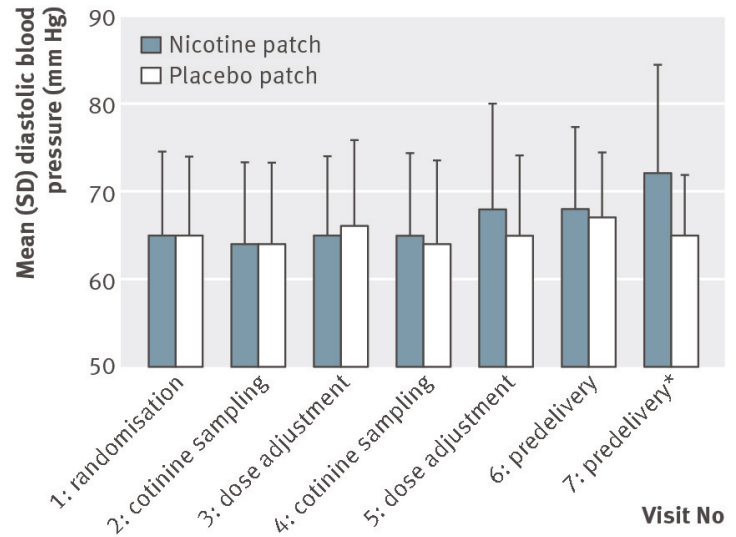

Fig 4 Diastolic blood pressure before (visit 1) and at each visit up to visit 7 (20 weeks after randomisation). *About one month before delivery. Group (treatment) by time interaction $\mathrm{P}=0.01$ 